Editor Jamshid Shirani, MD

Department of Cardiology, Geisinger Medical Center, 100 North Academy

Avenue, Danville, PA 17822, USA.

E-mail: jshirani1@geisinger.edu

\title{
Advanced Cardiovascular Imaging: The American Experience
}

Advanced noninvasive cardiovascular imaging has experienced major growth and technologic advances in the past decade and has provided new strategies for diagnosing and managing heart disease. The emergence of new imaging modalities has enabled a more comprehensive and pathophysiology-based approach to clinical cardiology. Such advances have led to new understandings of the initiation and progression of cardiovascular diseases. Professional organizations have had a central role in the development, standardization, proper application, and critical evaluation of established and newer modalities of cardiovascular imaging.

\section{Academy of Molecular Imaging (AMI)}

http://www.ami-imaging.org/

Managed by the American College of Radiology (ACR) and the ACR Imaging Network, the Academy of Molecular Imaging (AMI) consists of four councils: Institute for Clinical Positron Emission Tomography (PET), Institute for Molecular Imaging Science, Society of Noninvasive Imaging in Drug Development, and Institute for Molecular Technologies. The official journal of the AMI, Molecular Imaging and Biology, is published bimonthly. The website provides several educational tools, including a free image atlas of 18-fluorodeoxyglucose-PET and PET/CT.

\section{American Society for Nuclear Cardiology}

http://www.asnc.org/

Founded in 1993, the American Society for Nuclear Cardiology has about 5000 members. The society provides an annual scientific meeting and publishes a bimonthly journal, Journal of Nuclear Cardiology. The website offers information regarding accreditation processes, guidelines and standards, and training requirements for nuclear cardiology. Additionally, online educational materials are available, including the Case of the Month and the Corporate Partners' Case Library series. An online course for CT angiography and a Nuclear Cardiology Knowledge Self-Assessment Program are offered for a fee.

\section{American Society of Echocardiography (ASE)}

http://www.asecho.org/

This American Society of Echocardiography has about 14,000 members, publishes a monthly periodical titled The Journal of the American Society of Echocardiography, and hosts an annual scientific meeting. In the Education and Resources section, the website offers the Contrast Zone, which includes special education in contrast echocardiography with a detailed and up-to-date bibliography, and the Digital Zone, with information on digital echocardiography. Detailed core curricula for physicians and sonographers are posted on the website. Additionally, a Fellow Slide Set, consisting of PowerPoint presentations on many basic and advanced echocardiographic topics, is available online. A collection of guidelines and standards documents can be accessed here as well.

\section{Society for Cardiovascular Computed Tomography}

http://www.scct.org/

The Society for Cardiovascular Computed Tomography is the most recently developed (2005) and rapidly growing organization in the field of advanced cardiovascular imaging. Since 2007, the society has hosted an annual scientific meeting and has published the bimonthly Journal of Cardiovascular Computed Tomography. The website offers access to guidelines, position papers, 
appropriateness criteria, and news about this imaging modality. In addition, members have access to a lecture series on the basic principles of cardiac CT.

\section{Society for Cardiovascular Magnetic Resonance}

http://www.scmr.org/

The Society for Cardiovascular Magnetic Resonance hosts an annual scientific meeting and publishes the bimonthly Journal of Cardiovascular Magnetic Resonance. Beginning this year, this official publication is available as an open-access journal. The website offers many educational materials, including a cardiovascular MR atlas of static and moving images and a case of the week. Guidelines for training in cardiovascular MR are accessible on this site, and short- and longerterm training opportunities are posted. 